\title{
The factors perceived to influence the retention of information technology workers
}

\author{
M. Gaylard, M. Sutherland and C. Viedge* \\ Wits Business School, University of the Witwatersrand, \\ PO Box 98. Wits 2050, Republic of South Africa
}

Received March 2005

\begin{abstract}
The purpose of this study was to identify the most important variables for retaining information technology workers as their turnover has a range of negative consequences for their employing companies. Data was collected from 239 IT workers across three continents by means of an electronic questionnaire-based survey. The data was then subjected to a number of statistical analyses including factor analysis. The research established that the three factors perceived to most affect the retention of IT workers are, in order of importance; equity and enablement for high performance, a liberated and empowered culture, an effective and interactive communication channel between management and the employees.
\end{abstract}

*To whom all correspondence should be addressed.

\section{Introduction}

Companies have transitioned from the Industrial Age into the Information Age, during which competitive advantage has shifted from raw materials, capital and equipment to information, knowledge, ideas and management skills (Duffy, 1997). This has raised the notion of 'human capital' where people are seen not as a perishable resource to be consumed, but rather as a valuable commodity to be developed (Friedman, Hatch \& Walker, 1998). As a result, a whole new corporate paradigm is emerging in which corporate dependence on the employee is growing. However, during the transition, many companies have concentrated on cost cutting, outsourcing and downsizing. The side effect of these measures is that employee loyalty has significantly eroded and has given way to mobility and career self-preservation. As a consequence, turnover rates have been climbing.

The result is that business now confronts a serious challenge globally (Cappelli, 1999). On the one hand they recognise their increased dependence on the knowledge and skills of the right people, yet on the other hand, they can no longer rely on employee loyalty. As a result, traditional perceptions of what is owed and expected between employee and employer have been re-evaluated. Such perceptions are encapsulated by the concept of the 'psychological contract' (Rousseau, 1989). Attracting and keeping employees within this new contractual framework, has been referred to as 'the War for Talent’ (Herman \& Gioia, 2000).

According to Cappelli (2001), the Information Technology (IT) labour market exemplifies this unstable situation. IT workers are at the forefront of the war for talent (Johnson, 2000), and thus there is a need to understand why turnover is so great in IT jobs. For the purposes of this research, IT workers are defined as those workers engaged in the creation or maintenance of any or all of the following: IT strategy; hardware systems; software systems; infrastructure; processes; or related business processes, employed either by IT companies or by IT departments of non-IT companies.

Information is expanding at an unprecedented rate, and enormously rapid strides are being made in the technology for storing, organising and accessing the ever growing tidal wave of information. The impact of this is that the half-life of IT knowledge is a mere 2,5 to 5 years and is reducing all the time (Gartner Group, 2000). According to Cappelli (2001) this rapid obsolescence of knowledge is a major reason for the high level of 'churn' in the IT workforce. There is however no need for absolute retention of all IT employees as dynamic organisations require a certain level of turnover to remain energised and productive (Haskett, Jones, Loveman, Sasser \& Schlesinger, 1994). Gartner Group (2001) suggests that employers of IT workers are likely to concentrate more on the retention of those employees who have a greater conceptualisation of the context of the industry and the businesses they serve, than on those who simply have technical knowledge and skills.

Even after the IT 'dot com' meltdown of 2000, a number of recent surveys have shown that the IT sector has the highest turnover rates of all sectors (Bernthal \& Wellins, 2001; Cutter Consortium, 2001). The Gartner Group (2000) expects the demand for IT talent to outweigh supply by more than $20 \%$ through 2005 , and predicts that the dramatic shortage of qualified IT professionals remains one of the major challenges facing IT organisations today. This highlights the importance of managing retention in the IT sector.

A fundamental issue with high staff turnover is cost. Most organisations vastly under-estimate the true magnitude of 
turnover costs (Corporate Leadership Council, 1998b). This is because they consider only the more visible direct costs involved. The true cost of a worker leaving an organisation is not only the cost of hiring and training a replacement, but also the loss of institutional knowledge, lower office morale and lessened productivity (O'Keefe, 2000), the cost of loss of talent, productivity and quality shortfalls, and customer dissatisfaction (Corporate Leadership Council ,1998a). This total cost of turnover is not insubstantial and has been found to be $70 \%$ to $200 \%$ of the departing employee's annual salary (Michaud, 2000). Thus staff retention has become an important business issue and in order for companies to develop effective retention strategies, they need to understand the variables which contribute to the retention of their employees.

The literature points to a wide variety of often conflicting factors that may influence retention. In spite of the view that different employees are motivated and retained by different retention variables (Wickens,1995), there are several key areas which are repeatedly raised in the literature as being fundamental to retention.

\section{Job satisfaction}

The employee retention strategies of most companies are based on the premise that job satisfaction and retention are closely correlated (Corporate Leadership Council, 1999). Job satisfaction is a composite measure of many components of organisational life. However, research done by Corporate Leadership Council (1999) finds this premise to be untrue. They found that two-thirds of high value employees who intend to leave are actually satisfied with their current job.

\section{Financial reward}

The empirical findings on the role financial reward play in retaining individuals are contradictory. Williams \& Sunderland (1999:37) report that money was the most important extrinsic factor in retention in AON Consulting's 1998 survey of 1800 U.S. employees. On the contrary, a 1999 Hay Group study of more than 500,000 employees in 300 companies found that of the 50 retention factors surveyed, pay was the least important. Cappelli (2000) lists remuneration only as the initial way that a company gains its employees’ loyalty.

\section{Employability and personal growth}

Kaye \& Jordan-Evans (2000), report on the 1999 Hay Group study where it was found that the most important retention factor was career growth, learning and development. Tulgan (2001) takes it further, he shows that people are entirely preoccupied with growth opportunities. This is especially true in the IT industry where technology is changing so fast that skills very quickly become obsolete.

\section{The job itself}

Kinni \& Von Hoffman (2000) suggest that organisations can go a long way to improving the retention capability of the job by allowing greater autonomy and freedom, by providing challenging and meaningful work and by encouraging a flexible work arrangement. In a 1999 study by the UK's Roffey Park Management Institute, it was found that the main reason for staying in a job was the challenge it provided. Kinnear \& Sutherland (2000) found in their study of knowledge workers across different industry sectors that the tools and technology available to an employee are one of the four main variables influencing organisational commitment.

\section{The employee}

Personality attributes have been proposed as another dimension affecting organisational commitment (Arnold, 1995). Arnold found that a high internal locus of control was negatively correlated to organisational commitment. This would indicate that the more control that an employee perceives himself to have over his destiny, the less likely he is to be committed to an organisation and the more difficult it will be to retain such an employee. The degree to which the employee 'fits' into the organisation in terms of technical skills, leadership competencies, personal traits and values will also strongly influence the organisation's ability to retain the employee.

\section{Relationship with the boss}

Various research studies indicate that the relationship an employee has with his boss is the single most significant factor in influencing the employee's commitment level and the organisation's ability to retain the employee (Tulgan, 2001; Galagan, 2000; Kaye \& Jordan-Evans, 2000; Kinni \& Von Hoffman, 2000). Research by the Saratoga Institute shows that ' $50 \%$ of work-life satisfaction is determined by the relationship an employee has with his boss' (Kaye \& Jordan-Evans, 2000:33). Dobbs (2001) concurs that while compensation and career opportunities are important, most employees leave because of bad managers.

\section{The organisational culture and environment}

The literature shows that there are certain elements of organisational culture which have a strong and positive effect on staff retention. According to Kaye and JordanEvans (2000), Galagan (2000), Salopek (2000a) and Kinni and Von Hoffman (2000) these include: supporting work which employees are passionate about, caring about workers' private lives, employee wellness and values, and striving to align these with the rest of the team and the organisation; giving employees freedom to work in their own creative ways; and customising retention remedies for each employee individually, providing a nurturing, enjoyable and fun work environment, providing an environment of trust in which information flows freely and employees' views are respected. 


\section{Research objectives}

The literature highlights many variables that may influence an IT worker's decision to remain with a company. It is this workplace dynamic, together with the cost of turnover, that demands that companies swiftly turn their attention to identifying what the factors are, that contribute to the retention of their IT workers.

The objectives of this research were to establish:

- the variables which are most and least perceived to contribute to the retention of IT workers;

- the factors (themes underlying the variables) which are perceived to most contribute to the retention of IT workers;

- $\quad$ any significant relationships between an IT worker's intention to leave an organisation and their demographic attributes.

\section{Research methodology}

Data for this study was collected through the administration of an electronic questionnaire-based survey. Groenewald (1986), states that there are three characteristics of a survey: information is collected about different cases; a finite number of cases are registered; and surveys are executed in a circumscribed area at a given time.

\section{Population and sample}

The population selected for the research comprised all IT employees within a large multinational manufacturing organisation which operates in over 60 countries and has over 50000 employees. The company has a turnover of $£ 4,323$ billion per annum. Within the organisation, three sample organisations were identified: in Europe, Australia and South Africa. These three organisations were chosen because they were all sizeable organisations within the group and they were all English speaking organisations. This meant that the questionnaire did not need to be translated, so avoiding potential problems inherent in interpretation.

\section{Design and use of the questionnaire}

The questionnaire design (Leedy, 1997) took place in three stages: The first stage involved generating questions based on the literature review of the factors influencing retention. The second stage verified those variables by interviewing two human resource managers and two IT workers as to what they perceived were the key retention variables for IT workers. As a result of this verification stage, several new variables were identified. The third stage was the pilot study to determine the usability of the questionnaire. The questionnaire and the technology were modified to take into account the feedback received.

The final questionnaire included the following sections; demographics; a section on the fifty identified retention variables, soliciting ratings on a ten point numeric scale anchored at either end, to the question 'How important is this variable in my decision to remain with a company?'; and a section on the respondents' level of job satisfaction and intention to remain in their current organisation.

As the questionnaire was to be administered to over 300 people spread across more than twelve locations in Australia, the United Kingdom and South Africa, the organisation's wide-area network was utilised to distribute and administer the survey. The questionnaire was developed in Microsoft ASP.net, using Microsoft Visual Studio to develop a series of electronic web-enabled pages for capturing information. This consolidated workbook was then formatted to conform to the data layout required by the Number Cruncher Statistical System (NCSS).

\section{Limitations}

This study only considers employees of one multinational corporation. In spite of the fact that each of the group's corporate entities in the different countries manage their employees with a high degree of autonomy, generalisations about the applicability of the results across different organisations cannot be directly made. The research makes the assumption that IT workers' perception of which variables most influence their retention are those that actually do have the most influence on their retention.

\section{Results}

Of the 309 questionnaires sent out, 239 were returned, resulting in a return rate of 77,3 percent. Emory and Cooper (1991) state that 30 percent returns are satisfactory, hence a 77,3 percent return rate is excellent. The data collected via the numerical scales in the questionnaire was subjected to correspondence analysis in NCSS. This was done to rescale the rating of the fifty statements from ordinal to interval data in order to facilitate further statistical analysis (Bendixen \& Sandler, 1995).

\section{Sample demographics}

The distribution of the sample was as follows: Forth eight percent of the sample came from the United Kingdom, twenty one percent from Australia and thirty one percent from South Africa. Twenty percent were under thirty years of age and eighty percent older than that. Most respondents (53\%) claimed a medium level of job satisfaction. Only a very small portion of respondents (9\%) have a low level of job satisfaction, while $38 \%$ have a high level of job satisfaction.

\section{Research objective 1: The most influential variables}

The means of the rescaled data for the fifty variables relating to the question 'How important is this variable in my decision to remain with a company?' were rank ordered in order to establish which variables are perceived to be the most important to IT workers. The table below shows the top ten variables. 
Table 1: The top ten variables

\begin{tabular}{|c|c|c|}
\hline Ranking & Variables that influence retention & Mean \\
\hline 1 & Having a good balance between my work and home life. & 9,04 \\
\hline 2 & Having a good working relationship with my colleagues. & 8,85 \\
\hline 3 & Having an open and honest two-way communication channel with my direct manager. & 8,80 \\
\hline 4 & Being financially rewarded in accordance with my contribution and performance. & 8,77 \\
\hline 5 & Having a competitive market-related remuneration package. & 8,75 \\
\hline 6 & Being fairly rewarded relative to other employees, based on my experience, qualifications and performance. & 8,74 \\
\hline 7 & Working in an environment which allows a high level of autonomy to get the work done. & 8,73 \\
\hline 8 & Having the right tools to do my job well (PC’s, hardware, software applications etc.) & 8,70 \\
\hline 9 & Having a competent manager. & 8,61 \\
\hline 10 & Having a clear understanding of what is expected of me. & 8,60 \\
\hline
\end{tabular}

These variables can be summarised into the following five themes:

- Work/home balance

- Performance-related financial reward

- Clear and open communication channels

- Performance-enabling environment

- Excellent manager

\section{Research objective 2: Least important retention variables}

Table 2 below shows the items considered to be least important by the IT workers in influencing their retention.

These least important variables can be summarised into the following four themes:

- Change and lack of stress

- Traditional fringe benefits of medical aid and share options

- Social interaction

- Company vision and performance appraisal system.

Research objective 3: The factors underlying the variables

An objective was to determine whether the retention variables may be grouped into meaningful underlying factors. In order to do this a factor analysis using Principle Component Analysis and Varimax Rotation was performed on the re-scaled data. According to Cooper (1998:560), 'factor analysis looks for patterns amongst the variables to discover if an underlying combination of the original variables (a factor) can summarise the original set'. The number of factors making up the factor solution was determined by the following: each factor having an eigenvalue greater than one; the point at which the screeplot alters significantly; and the factor solution which provides for a logical interpretation. A six factor solution which accounted for $72,97 \%$ of the total absolute variation was selected. All variables with loadings greater than 0,45 were included in the relevant factors. Each factor was then given a descriptive label based on the variables within the factor. Cronbach's alpha co-efficient was used to assess the internal reliability of each of the factors. An alpha coefficient of 0,7 or higher is acceptable (Cooper, 1998). All six factors met these criteria.

Tables 3 to 8 below encapsulate the six factors that have been identified. Each table lists the statements that associate with the factor concerned, the loading (degree of association) that each statement has with the factor and the ranked importance related to each statement from the original set of analyses. All the statements within each factor are loaded in the same direction. The eigenvalue of each factor is given below each table. In order to determine the perceived relative importance of the six factors each statement mean was weighted by the statement loading. The weighted average of the statement means was then assumed to indicate the relative importance of each factor. The factors have been numbered in accordance with their perceived relative importance. It was decided to use the factor means and not the eigenvalues to determine the relative importance of each factor as the aim of the study was to determine which factor had been more highly ranked by the respondents rather than a trying to determine the percentage of variation accounted for by each factor. 
Table 2 : The bottom ten variables

\begin{tabular}{c|l|c}
\hline Ranking & \multicolumn{1}{|c}{ Variables that influence retention } & Mean \\
\hline 41 & Having a well-designed and adhered-to performance appraisal system. & 7,60 \\
\hline 42 & Having a job which does not contain too many overly stressful, tedious or less than satisfactory elements. & 7,57 \\
\hline 43 & Having a clearly articulated corporate vision, goals and plans on how to achieve these goals. & 7,53 \\
\hline 44 & Having career paths that allow me to become an expert in my field without being penalised for not taking & 7,47 \\
\hline 45 & Being able to do project work. & 7,26 \\
\hline 46 & Working in an ever-changing environment. & 7,12 \\
\hline 47 & Receiving medical aid benefits. & 6,93 \\
\hline 49 & Having the freedom and time to interact socially with other employees at work. & 6,90 \\
\hline 50 & Having a close colleague or good friend at work. & 6,38 \\
\hline
\end{tabular}

Table 3: Variables associated with factor one

\begin{tabular}{|c|c|c|}
\hline Loading & Statement & $\begin{array}{c}\text { Ranked } \\
\text { Importance }\end{array}$ \\
\hline$-0,63$ & Having a good balance between my work and home life. & 1 \\
\hline$-0,61$ & Being fairly rewarded relative to other employees, based on my experience, qualifications and performance. & 6 \\
\hline$-0,58$ & Being financially rewarded in accordance with my contribution and performance. & 4 \\
\hline$-0,58$ & Having a good working relationship with my colleagues. & 2 \\
\hline$-0,56$ & Having a competitive market-related remuneration package. & 5 \\
\hline$-0,56$ & Having a clear understanding of what is expected of me. & 10 \\
\hline$-0,54$ & Having the opportunity to do what I do best, every day. & 27 \\
\hline$-0,53$ & Having a competent manager. & 9 \\
\hline$-0,50$ & Knowing that my skills and experience are sufficient for the job at hand. & 19 \\
\hline$-0,49$ & Having the right tools to do my job well (PC’s, hardware, software applications, accessories etc.) & 8 \\
\hline$-0,48$ & Having a job which does not contain too many overly stressful, tedious or less than satisfactory elements. & 42 \\
\hline$-0,47$ & Having a manager who really cares for me as a human being. & 24 \\
\hline$-0,46$ & Having an open and honest two-way communication channel with my direct manager. & 3 \\
\hline$-0,46$ & Having my inputs, opinions and the work that I produce duly considered, praised and rewarded where due. & 13 \\
\hline$-0,45$ & Having a sense of security that my job is not threatened and is mine as long as I'd like it. & 28 \\
\hline$-0,45$ & Having sufficient leave and the ability to exercise it when most suitable to me. & 14 \\
\hline
\end{tabular}


The factor mean was 8,53 . The eigenvalue for this factor is 7,16 and this factor accounts for $19,98 \%$ of the absolute variation in the data. The statements that load onto this factor are concerned with two broad aspects. The first is a sense of equity and balance in the employment relationship - be this in fairness of the salary, the balance between work and home demands, and the right to not having the job taken away unfairly. The second is a need to have the right tools, skills, communications and management to facilitate high performance output. In bringing these two broad aspects together, this factor has been named 'Equity and Enablement for High Performance'.

This is the factor which is perceived to be of most importance. It accounts for nearly $20 \%$ of the absolute variation in the data. Also, ten of the individual items comprising this factor fall within the first quartile of important variables in IT workers' retention cognitions. This finding supports Williams and Sunderland (1999:37) when they write: 'If you think that money is a secondary issue in employment retention, think again'. The concept of 'Fairness and Equity', however, has not been a well discussed theme in the literature. There is mention of the importance of work/home balance by Kaye and JordanEvans, (2000) but this has fallen under the banner of 'Organisation Culture'. Similarly, all references to pay and salary seem to be grouped in the literature under the banner of 'Financial Reward' (Williams \& Sunderland, 1999; Corporate Leadership Council, 1998b; Cappelli, 2000; Dibble, 1999). These research findings introduce the concept of 'Equity and Fairness' as a broad underlying theme that underpins both financial reward as well as elements of organisational culture. Kinnear and Sutherland (2000) found that tools and technology are one of the four main variables influencing organisational commitment in knowledge workers. This is echoed in Drucker (1989) and McNeese-Smith (1996). This is strongly supported in the research findings.

Table 4: Variables associated with factor two

\begin{tabular}{|c|c|c|}
\hline Loading & Statement & $\begin{array}{c}\text { Ranked } \\
\text { Importance }\end{array}$ \\
\hline$-0,56$ & Being in an environment which encourages use of initiative without fear of punishment or failure. & 11 \\
\hline$-0,56$ & Having a job which allows me to be creative and innovative. & 15 \\
\hline$-0,47$ & Working in an environment which allows me a high level of autonomy and freedom to get the work done. & 7 \\
\hline$-0,46$ & Working in a culture of excellence and continuous improvement. & 16 \\
\hline$-0,46$ & $\begin{array}{l}\text { Having opportunities to develop new skills and knowledge and to use this in challenging and interesting } \\
\text { ways. }\end{array}$ & 12 \\
\hline
\end{tabular}

The factor mean was 8,51 . The eigenvalue for this factor is 3,65 and this factor accounts for $10,19 \%$ of the absolute variation in the data. The statements that load onto this factor are concerned with having autonomy and freedom to reach one's potential, to extract greater challenge and interest from employment and to be able to fail without fear. Therefore, this factor has been named 'Liberated and Empowered Culture'.

This is the second most important factor. This factor accounted for $10,19 \%$ of the absolute variation in the data. All of the rankings of the factor items are evenly spread across the top two quartiles of important variables in IT workers' retention cognitions. IT workers want to work independently and in a culture where excellence and continuous improvement are expected. The importance of this factor supports Salopek's (2000b) finding that 'Retention Leaders' need to be relentless in the pursuit of continuous improvement. It also supports Wickens (1995) and Kaye and Jordan-Evans (2000) when they emphasise that knowledge workers need autonomy and discretion in executing their own work. Similarly, it supports Drucker's (1974) assertion that this is the age of individualism and Kinnear and Sutherland's (2000) finding that freedom to act was one of the four prime determiners of the organisational commitment of knowledge workers. This factor shows the very high importance of a liberated and empowered culture in IT workers' decisions to remain with a company. 
Table 5: Variables associated with factor three

\begin{tabular}{c|l|c}
\hline Loading & \multicolumn{1}{|c}{ Statement } & $\begin{array}{c}\text { Ranked } \\
\text { Importance }\end{array}$ \\
\hline$-0,62$ & Having an open and honest two-way communication channel with my direct manager. & 3 \\
\hline$-0,59$ & Having a clearly articulated corporate vision, and plans on how to achieve these goals. & 43 \\
\hline$-0,57$ & Receiving clear and frequent communications on strategy, goals and plans. & 33 \\
\hline$-0,53$ & Having a sense of loyalty to remain with and continue to serve the organisation. & 26 \\
\hline$-0,49$ & Working in an organisation which has clear and sound governance over its core activities. & 38 \\
\hline$-0,49$ & Having a well-designed and adhered-to performance appraisal system. & 20 \\
\hline$-0,49$ & Working for a company which identifies and looks after its high performers. & 17 \\
\hline$-0,48$ & Having an empowering and constructive working relationship with my direct manager. & 22 \\
\hline$-0,48$ & Having a clear understanding of my goals, and why they are important in ensuring the success of the \\
\hline$-0,45$ & Havganisation. & 13 \\
\hline
\end{tabular}

The factor mean was 8,10 . The eigenvalue for this factor is 5,37 and this factor accounts for $14.99 \%$ of the absolute variation in the data. The statements that load onto this factor are primarily concerned with the nature and effectiveness of the communication channel between employees and their direct managers. Therefore, this factor has been named 'Effective and Interactive Communication Channel’.

The individual aspects deal with the quality of the communications being open and honest, empowering and constructive. They also cover the content of such communications, including vision, goals, plans, strategy, praise, performance information and feedback, as well as feedback of personal inputs and opinions. This factor had the third highest factor mean of all the six factors and accounted for $14,99 \%$ of the absolute variation in the data. Perhaps this factor is best summed up in the words of Kaye and Jordan-Evans (2000:33) when they write that approximately ' $50 \%$ of work-life satisfaction is determined by the relationship an employee has with his boss'. It is interesting that the respondents found the nature of the communications to be significantly more important than the content that is being communicated. This result echoes the findings of Galagan (2000), Kaye and Jordan-Evans (2000) and Kinni and Von Hoffman (2000) who advocate open, honest, truthful and respectful two-way communication as being key for building loyalty and improving retention. This factor shows that IT workers hold the opinion that having an effective and interactive communication channel with their direct managers is important to them.

Table 6: Variables associated with factor four

\begin{tabular}{c|l|c}
\hline Loading & \multicolumn{1}{|c}{ Statement } & $\begin{array}{c}\text { Ranked } \\
\text { Importance }\end{array}$ \\
\hline$-0,72$ & $\begin{array}{l}\text { Knowing that there are strong career growth possibilities and that the organisation will align my career path } \\
\text { with my personal interests and goals. }\end{array}$ & 18 \\
\hline$-0,52$ & Having opportunities to obtain global exposure and experience. & 39 \\
\hline$-0,46$ & Having a clearly articulated corporate vision, goals and plans on how to achieve these goals. & 43 \\
\hline$-0,46$ & Having the ability to change careers within the same organisation. & 36 \\
\hline
\end{tabular}

The factor mean was 7,86 . The eigenvalue for this factor is 3,95 and this factor accounts for $11,03 \%$ of the absolute variation in the data. The statements that load onto this factor are concerned with individual growth possibilities and opportunities to further skills and careers. Therefore, this factor has been named 'Environment Rich in Personal Growth Opportunities’.

This is the fourth most important factor. This factor accounted for $11,03 \%$ of the absolute variation in the data. Three of the rankings of the factor items are in the lowest quartile while the other one is in the $2^{\text {nd }}$ quartile. This finding is of interest as a great deal of literature (Tulagn, 2001; Kaye \& Jordan-Evans,2000) states that knowledge workers are pre-occupied with personal growth opportunities. Hence it was expected that these individual variables would have been ranked far higher than they were. However Table 1 indicates they do want to be skilled to carry out their jobs and be given the correct tools to do the job. It thus appears that the IT workers in this study are concerned about enablement to do the job rather than being skilled in order to have a high level of career mobility. 
Table 7: Variables associated with factor five

\begin{tabular}{c|l|r}
\hline Loading & Statement & $\begin{array}{c}\text { Ranked } \\
\text { Importance }\end{array}$ \\
\hline$-0,65$ & Being part of a pension or provident scheme. & 31 \\
\hline$-0,65$ & Receiving medical aid benefits. & 47 \\
\hline$-0,56$ & Being given share options in the company. & 50 \\
\hline$-0,51$ & Having sufficient leave and the ability to exercise it when most suitable to me. & 14 \\
\hline
\end{tabular}

The factor mean was 7,36 . The eigenvalue for this factor is 2,78 and this factor accounts for $7,77 \%$ of the absolute variation in the data. The statements that load onto this factor are concerned with the standard 'transactional' elements found in most employment contracts (Armstrong \& Murlis, 1998). Therefore, this factor has been named Standard Employment Contract Benefits. This is the fifth most important factor. The items all relate to explicit terms and conditions that are fairly commonly written into employment contracts. They are pension or provident fund membership, medical aid benefits, share options and leave provisions.

Table 8: Variables associated with factor six
The fact that this largely 'transactional' factor is ranked as relatively unimportant would indicate that the psychological contract for IT workers would be high in 'Relational' socio-emotional obligations, as psychological contracts high on one type of obligation are usually low on the other (MacNeil, 1985). This factor shows the perceived low importance of standard employment benefits in retaining IT workers.

\begin{tabular}{l|l|c}
\hline Loading & Statement & $\begin{array}{c}\text { Ranked } \\
\text { Importance }\end{array}$ \\
\hline$-0,62$ & Having a close colleague or good friend at work. & 49 \\
\hline$-0,52$ & Having the freedom and time to interact socially with other employees at work. & 48 \\
\hline$-0,52$ & Having fun on the job. & 25 \\
\hline$-0,50$ & Working in an ever-changing environment. & 46 \\
\hline
\end{tabular}

The factor mean was 7,11 . The eigenvalue for this factor is 3,23 and this factor accounts for 9,01\% of the absolute variation in the data. The statements that load onto this factor are concerned with social exchanges and a recognition of employees as social beings. Therefore, this factor has been named 'Social Interaction'.

This is the least important factor of the six, with a factor mean of 7,11 . Three of the four factor items are in the bottom five variables ranked in order of importance, while the fourth variable, 'Having fun on the job', is ranked midway in the importance rankings. According to the literature, one of the key elements of corporate culture is an enjoyable and fun work environment (Galagan, 2000; Kaye \& Jordan-Evans, 2000; Kinni \& Von Hoffman, 2000; Salopek, 2000a). The research findings, however, do not support this at all. Although social interaction has been found to form a clear factor, it is considered unimportant in IT workers' decisions to remain with a company.

\section{Summary of factor analysis}

The factor analysis reveals (based on the factor means) the three factors that were found to be most important to retaining knowledge workers are: equity and enablement for high performance; a liberated and empowered culture; and interactive and effective communication. Issues that are relatively unimportant are social interaction, standard employment contract benefits and an environment rich in personal growth opportunities. However it must be noted that a number of the variables occur in more than one of the factors and hence the factors are not truly independent of each other, there are thus possible interrelationships between latent variables.

\section{Research objective 4: Intention to leave relationships}

The relationship between IT workers' intention to leave and: country of residence, age and level of job satisfaction were explored. The first two of these relationships were tested via 
chi-squared tests of dependence at the 0,05 significance level. In both cases the null hypotheses were not rejected and hence country of residence and age are independent of plans to leave the organisation.

The relationship between 'Level of Satisfaction' and 'Intention to Leave' was carried out using a Spearman's rank order correlation which was found to be $-0,426$. This indicates that there is a significant inverse relationship between job satisfaction and intention to leave at a significance level of 0,05. In other words, high levels of job satisfaction tend to be moderately associated with low intention to leave. This contradicts the findings of The Corporate Leadership Council (1999) who assert that counter-intuitively, job satisfaction is an unimportant predictor of intention to leave an organisation. Thus this research has shown that overall job satisfaction is important in retaining IT employees and the research has determined a number of variables that are influential in retaining these key employees. The research has highlighted those variables that are most important, as well as those whose importance is relatively small. Figure 1 below draws together and graphically displays both the three factors that were perceived to be most important in underpinning the retention of IT workers, and the 15 variables that were found to be most important. As a number of the variables occurred in more than one factor, there is some shared variance between the factors.

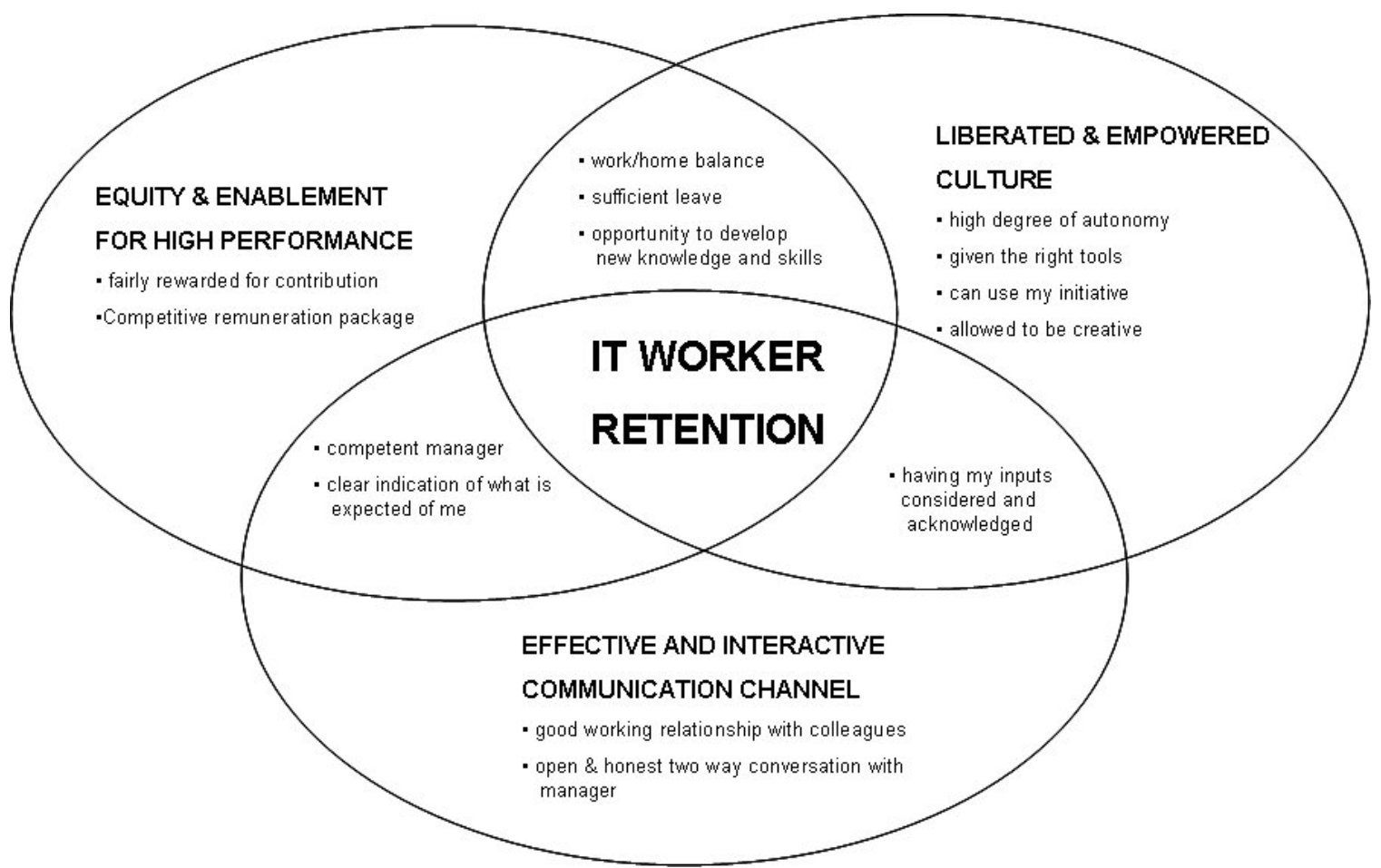

Figure 1: Issues perceived to affect the retention of IT workers

\section{Recommendations to management}

The findings of this study suggest that direct line managers of IT workers need primarily to build an effective communication channel with their staff. This channel should regularly be used to discuss and understand the factors that have been identified as important to retaining IT workers. That is, they must understand the extent of imbalance between individuals' home/work life, address aspects of perceived unfairness particularly with regard to remuneration issues; acknowledge the contribution of the individual, and determine if further training or other "tools" to enable higher performance are needed. It is important that the manager translates employee expectations into high level goals providing a broad scope of responsibility, focussing on end results rather than the process of how these results should be attained. This would provide for a high degree of autonomy and enable the use of personal initiative.

This study suggests that Human Resource managers in companies employing IT workers need to understand: the full costs (both direct and indirect) associated with their staff turnover as compared with the cost of their strategies to enhance retention; market internally the equity of the salaries that are being paid; ensure that management competencies are defined and that managers of IT workers are selected accordingly, and are not simply promoted into management positions because of good performance in technical positions; not concern themselves with building a socially interactive environment.

\section{Areas for future research}

It would be interesting to understand whether the same retention variables and factors that apply to full-time IT employees, also apply to IT contractors. Secondly as the three sub-samples in this study were from English speaking socio-corporate cultures, the results should be tested in other cultures, such as in Japan or India. The results of such research would show how universal the findings of this study are. 


\section{Conclusion}

Understanding the levers available to influence the turnover cognitions of IT workers is fundamental to affecting their retention. This study has contributed to the body of knowledge regarding the retention of these workers, especially as the results show that IT workers have particular retention needs which differ from those reported in the general retention literature. It has surveyed a large sample across three continents to highlight the most important retention factors. It is hoped that this new knowledge can be successfully incorporated into organisational thinking to reduce IT staff turnover costs. In turn this should assist in the attainment of corporate strategic objectives.

\section{References}

Armstrong, M. \& Murlis, H. 1998. Reward management, London: Biddles Ltd.

Arnold, C. 1995. 'Some antecedents of employee commitment and their influence on job performance: a multi-foci study', South African Journal of Business Management, 26(4):25-135.

Bendixen, M. \& Sandler, M. 1995. 'Converting verbal scales to interval scales using correspondence analysis', Management Dynamics: Contemporary Research, 4(1):3250 .

Bernthal, P. R. \& Wellins, R. S. 2001. 'Retaining talent: A benchmarking study', HR Benchmark Group, 3(2). [online] URL:http://www.ddiworld.com/pdf/CPGN60.pdf]. Accessed 22 August 2003.

Cappelli, P. 1999. The new deal at work. Boston: Harvard Business School Press.

Cappelli, P. 2000. 'A market-driven approach to retaining talent', Harvard Business Review, 30(2):87-99.

Cappelli, P. 2001. 'Why is it so hard to find information technology workers?', Organizational Dynamics, January February: 103 - 111.

Cooper, D. R. 1998. Business research methods. New York: McGraw Hill.

Corporate Leadership Council. 1998a. Employee retention. Washington, D.C: Corporate Executive Board.

Corporate Leadership Council. 1998b. Addressing systematic drivers of dissatisfaction. Washington, D.C: Corporate Executive Board.

Corporate Leadership Council. 1999. Salient findings on the career decisions of high value employees. Washington, D.C: Corporate Executive Board.

Cutter Consortium. 2001. Shortage of IT staff continues to plague business. [online] URL: http://www.cutter.com/consortium/press/010829.html.

Accessed 14 September 2003.

Dibble, S. 1999. Keeping your valuable employees. New York: John Wiley \& Sons Inc.

Dobbs, K. 2001. 'Knowing how to keep your best and your brightest', Workforce, April: 57-60.

Drucker, P. F. 1974. Management. London: Heinemann.

Drucker, P. F. 1989. The new realities. Oxford: Heinemann Professional Publishing Ltd.

Duffy, N. 1997. 'The knowledge age and its significance for business. In Leveraging Knowledge for Business Performance. The Book of the First Southern African Knowledge Management Conference. Johannesburg: University of the Witwatersrand, pp.17-23.

Emory, C. W. \& Cooper, D. R. 1991. Business research methods. 4th Edition. Boston: R. R. Donnoly and Sons Company.

Friedman, B., Hatch, J. \& Walker, D. 1998. Delivering on the promise. New York: The Free Press.

Galagan, P.A. 2000. The Brainy Bunch. Training and Development, April, 44-46

Gartner Group. 2000. Gartner's ten year vision. Gartner Africa IT Convention and Expo 2000, Sun City, $23^{\text {rd }}$ July.

Gartner Group. 2001. Workforce strategies: Building tomorrow's workforce today. Gartner Symposium/ITexpo Africa 2001, Sandton Convention Centre, Johannesburg, $1^{\text {st }}$ August.

Groenewald, J. P. 1986. Social research design and analysis. Stellenbosch: Stellenbosch University Publishers and Booksellers.

Haskett, J. L., Jones, T. O., Loveman, G. W., Sasser, W. E. \& Schlesinger, L. A. 1994. 'Putting the service-profit chain to work', Harvard Business Review, 72(2):164-174.

Herman, R. E. \& Gioia, J. L. 2000. How to become an employer of choice. Winchester Virginia: Oakhill Press.

Johnson, M. 2000. Winning the people wars: Talent \& the battle for human capital. London: Prentice-Hall.

Kaye, B. \& Jordan-Evans, S. 2000. 'Retention: Tag, you're it!', Training and Development, April: 29-34.

Kinnear, L. \& Sutherland, M. 2000. 'Determinants of organisational commitment amongst knowledge workers', South African Journal of Business Management, 31(3):106112.

Kinni, T. \& Von Hoffman, C. 2000. 'Employee retention: What managers can do', Harvard Management Update, 5(4):1-5. 
Leedy, P. D. 1997. Practical research planning and design. New Jersey: Merrill.

MacNeil, I. R. 1985. 'Relational contract: What we do and do not know’, Wisconsin Law Review, 3, 483-525.

McNeese-Smith, R.. N. 1996. 'Increasing employee productivity, job satisfaction, and organisational commitment', Hospital and Health Services Administration, 41(2):160-175.

Michaud, L. 2000. The value of retaining employees. Agency Sales Magazine, 30(11), 25-27.

O'Keefe, T. 2000. 'Lost employee costs more than just a paycheck', Atlanta Business Chronicle. [online] URL: http://www.amcity.com/atlanta. Accessed 28 February 2003.

Rousseau, D. M. 1989. 'Psychological and implied contracts in organisations', Employee Rights and Responsibilities Journal, 2(2):12 - 139.

Salopek, J. J. 2000a. 'Career centered', Training and Development, April: 24-26.

Salopek, J.J. 2000b. 'Retention rodeo', Training and Development, April: 20-23.

Tulgan, B. 2001. Winning the talent wars. New York: W.W. Norton \& Company. Inc.

Wickens, P. 1995. The ascendant organisation. Basingstoke: McMillan Press Ltd.

Williams, V. L. \& Sunderland, J. E. 1999. 'New pay programs boost retention’, Workforce, 4(1):36-40. 